\title{
Harnessing High-Altitude Solar Power
}

\author{
Guglielmo S. Aglietti, Stefano Redi, Adrian R. Tatnall, and Thomas Markvart, Member, IEEE
}

\begin{abstract}
As an intermediate solution between Glaser's satellite solar power (SSP) and ground-based photovoltaic (PV) panels, this paper examines the collection of solar energy using a highaltitude aerostatic platform. A procedure to calculate the irradiance in the medium/high troposphere, based on experimental data, is described. The results show that here a PV system could collect about four to six times the energy collected by a typical U.K.-based ground installation, and between one-third and half of the total energy the same system would collect if supported by a geostationary satellite (SSP). The concept of the aerostat for solar power generation is then briefly described together with the equations that link its main engineering parameters/variables. A preliminary sizing of a facility stationed at $6 \mathrm{~km}$ altitude and its costing, based on realistic values of the input engineering parameters, is then presented.
\end{abstract}

Index Terms-Energy conversion, photovoltaic ( $\mathrm{PV}$ ) power systems, PV space power systems, power conversion, solar energy, solar power satellites, solar radiation, terrestrial atmosphere.

\section{NOMENCLATURE}

$A_{\text {cond }} \quad$ Cross-sectional area of the conductor.

$\mathrm{AM}_{\mathrm{REL}} \quad$ Relative air mass.

$B \quad$ Aerostat buoyancy.

$C_{d} \quad$ Aerostat drag coefficient.

$D \quad$ Aerostat drag force.

$\Delta h \quad$ Length of vertical segment of light beam path.

$d z, \Delta z \quad$ Length of inclined segment of light beam path.

e Solar elevation angle.

$E_{B} \quad$ Total beam irradiation.

$g \quad$ Gravity acceleration $\left(9.81 \mathrm{~m} / \mathrm{s}^{2}\right)$.

$h \quad$ Altitude.

$H \quad$ Local hour angle.

I Light beam intensity.

$I_{0} \quad$ Light beam intensity before entering the atmosphere.

$p_{\text {REL }} \quad$ Relative pressure.

$P_{\text {gen }} \quad$ Power generated by the PV system.

$r_{\mathrm{Al}} \quad$ Resistivity of the aluminum.

$R \quad$ Radius of the balloon.

$S \quad$ Overall length of the conductor.

$S_{T} \quad$ Length of the tether.

$T \quad$ Tension in the tether.

$v \quad$ Wind velocity.

V Voltage.

Manuscript received June 3, 2008; revised July 22, 2008. Current version published May 19, 2009. Paper no. TEC-00201-2008.

The authors are with the School of Engineering Sciences, University of Southampton, Southampton SO17 1BJ, U.K. (e-mail: gsa@ soton.ac.uk).

Color versions of one or more of the figures in this paper are available online at http://ieeexplore.ieee.org.

Digital Object Identifier 10.1109/TEC.2009.2016026

Vol
$W_{\text {aero }}$
$W_{\text {cond }}, W_{\text {fib }}$,
$W_{\text {tether }}$
$\alpha$
$\delta$
$\delta_{\text {aero }}, \delta_{\text {cells }}$
$\delta_{\text {cond }}, \delta_{\text {fib }}$
$\gamma$

$\eta$
$\theta_{z}$
$\rho_{\text {air }}, \rho_{\text {gas }}$
$\sigma_{u}$
$\varphi$
$\Phi$

Volume of the aerostat. Weight of aerostat including PV devices.

Weight of conductor, reinforcing fibers, and total weight of the tether. Extinction parameter. Sun declination.

Area density of the envelope material and PV cells.

Density of conductor and tether reinforcing fibers.

Fraction of the envelope surface covered by PV cells.

Efficiency.

Solar Zenith angle.

Densities of air and gas filling the aerostat.

Tether reinforcing fibers strength.

Geographical latitude.

Solar flux.

\section{INTRODUCTION}

$\mathbf{T}$ HE DEVELOPMENT of new and cost-effective methods to harness renewable energy has become crucial to maintain the energy supply that underpins our society, and solar power is one of the main candidates to make a substantial contribution to fulfil our future energy requirements.

One of the major issues in the use of ground-based photovoltaic (PV) panels to harvest solar power is the relatively low energy density that is compounded by the fact that the power output of the devices is strongly dependent on the latitude and weather conditions. These factors have particularly hindered the diffusion of PV in several countries with cloudy climates (e.g., north European countries). On the other hand, areas with high solar irradiations (e.g., African deserts; see [1]) are remote from most users and the losses over thousands of miles of cables and the political issues entailed in such a large project, severely reduce the economic advantages.

A completely different approach was proposed by Glaser [2] in the 1970s, and his idea has captured the imagination of scientists up to this day. The basic concept was to collect solar energy using a large satellite (which would be able to capture the full strength of the solar radiation continuously), and transmit it to the ground using microwave radiation. The receiving station would then convert the microwave radiation into electric energy to be made available to the users. The original concept was revisited in 1995 [3] in view of the considerable technological advances made since the 1970s, and research work on this concept is still ongoing. However, a mixture of technical issues (such as the losses in the energy conversions and transmission), safety concerns (regarding the microwave beam linking the satellite with the ground station), and cost, have denied the 
practical implementation of this concept. The latter is a substantial hurdle as the development of satellite solar power (SSP) cannot be carried out incrementally, in order to recover part of the initial cost during the development, and use it to fund the following steps, but it requires substantial funding upfront (tens of billions of dollars according to [3]) before there is any economical return.

As a compromise between Glaser's SSP and ground-based PV devices, it is proposed in this paper to collect the solar energy using a high-altitude aerostatic platform [4], [5]. This approach allows most of the issues related to the weather condition to be overcome, as the platform will be above the clouds except for very extreme weather situations. At the same time, as the platform is above the densest part of the troposphere, the sun beam will travel through considerably less air mass than if it was on the ground (in particular, for early morning and evening), and this will further improve the energy output. Therefore, this method enables considerably more solar power to be collected than on the ground (in this paper, it will be shown that at altitudes above $6 \mathrm{~km}$, it is possible to collect over four times more energy than using panels fixed on the ground in the U.K.). In addition, the mooring line of the platform can be used to transmit the electric energy to the ground in relative safety and with low electrical losses. Although this approach enables between onethird and half of the energy that could be harvested using an SSP, the cost of the infrastructure is orders of magnitude lower, and this approach allows an incremental development with a cost to first power, i.e., a few orders of magnitudes smaller than that necessary for SSP.

Most researchers up till now have proposed harvesting energy at high altitude by exploiting the strong winds existing in the high atmosphere [6] by using flying electrical generators (FEG), that are essentially wind turbines collecting wind power at altitudes from a few hundred meters [7] to $10 \mathrm{~km}$ or more altitude (to exploit the powerful jet stream currents).

The extraction of this energy using the type of machines proposed, for example, by Roberts in [6], although feasible and most probably economically viable, is relatively complex in mechanical terms. One of the issues is that in low wind, the machine (which is heavier than air) needs to reverse its energy flow and take energy from the ground to produce enough lift to support itself and the tether. Alternative designs like the MAGENN in [7] overcome this problem using a lighter-than-air approach so that the buoyancy keeps it in flight all the time. However the mechanical complications are still considerable.

The exploitation of solar energy at high altitude may therefore be simpler in engineering/mechanical terms, and provide a very predictable/reliable source. One of the crucial steps to demonstrate the viability of the concept is a reliable calculation of the solar energy available as a function of the altitude, and this is the subject of the first section of this paper. The concept of the aerostat for solar power generation (ASPG) is then described together with the equations that link its main engineering parameters/variables, and a preliminary sizing of an ASPG, based on the realistic values of the input engineering parameters is presented. Finally, a section on costing shows how this concept could provide a viable method to harvest solar energy and to transform it into electricity for ground users.

\section{Solar IRRAdiance VARiation With Altitude}

Solar radiation traveling through the atmosphere is attenuated by two main kinds of processes. The first process is defined as scattering and it involves the air molecules (Rayleigh scattering) and the larger particles that can change the direction of the photons after an interaction (Mie scattering). The other main process is the molecular absorption, in which the energy of the photons is converted into some other forms. In both these processes, energy is removed from the beam of light. The total attenuation of the light, traveling through a mean is known as extinction [8]. In the case of the Earth's atmosphere, most of the attenuation is due to scattering. As a result of these processes, the global solar radiation falling on a surface can be divided into two main components: direct (or beam) and diffuse. For low angles of incidence of the sun beam and/or a cloudy sky, the beam component can be very low so that most of the energy captured (global) is actually the diffused component.

Both scattering and absorption strongly depend on the atmospheric characteristics that the sun beam finds along its path from space to the ground. As a consequence, it is important to define these properties at various altitudes above the ground [9]. However, in practice, most of the published data are concerned with the evaluation of the intensity of the radiation (irradiance) at the ground level, whereas for this application, it is necessary to assess the irradiance at the altitude where the aerostat is due to operate. To achieve this objective, mathematical models describing the attenuation of the sun beam traveling to Earth in clear sky conditions can be integrated with real data describing the further attenuation produced by the presence of clouds, to obtain a reliable assessment of the irradiance at a specific altitude. The mathematical procedure is described in the next sections, and the real dataset including the effect of the clouds at various altitudes was provided by the Cloudnet Project [10] The data contain extinction parameters (i.e., the parameter describing the sun beam attenuation) obtained from Radar/Lidar measurements at Chilbolton Observatory, U.K.

\section{A. Atmospheric Extinction Modeling}

The attenuation of a beam of light traveling through the Earth's atmosphere is defined as atmospheric extinction, and can be quantitatively described by the extinction parameter $\alpha$. Considering a light beam of intensity $I$ going through a length $d z$ of atmosphere characterized by an extinction $\alpha$, the loss of intensity due to the attenuation process, can be expressed with the following differential [8]:

$$
\frac{d I}{I}=-\alpha d z
$$

In the case of the Earth's atmosphere, the path length from the top of the atmosphere to the ground, can be divided in segments of constant extinction $\alpha_{i}$ and length $d z_{i}$. Therefore, (1) can be rewritten to estimate the intensity of the beam that reaches the 


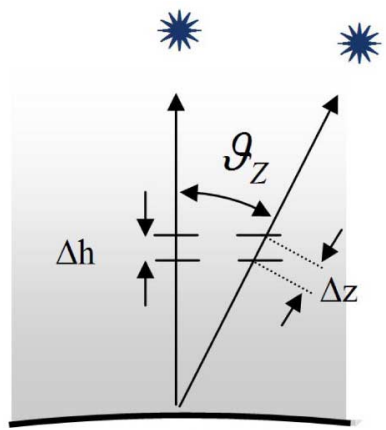

Ground level

(a)

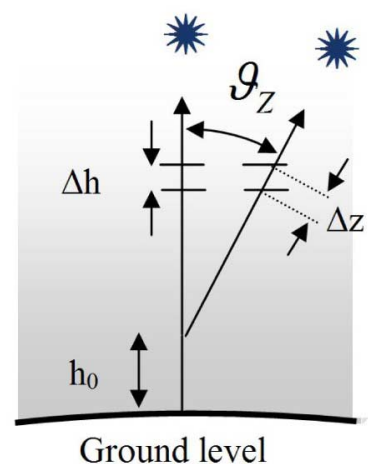

(b)
Fig. 1. Solar Zenith and beam path relation for ground level and altitude $h_{0}$. (a) Beam paths to ground level. (b) Beam paths to the altitude $h_{0}$.

ground as

$$
I=I_{0} e^{\sum-\alpha_{i} \cdot \Delta z_{i}}
$$

where $I_{0}$ is the irradiance before the beam enters the atmosphere and the sum considers all the segments crossed by the light beam.

With reference to Fig. 1(a), to evaluate the path length in the Earth atmosphere, an important parameter is the relative Air Mass $\mathrm{AM}_{\mathrm{REL}}$. This parameter defines the ratio between the air mass crossed by a light beam (at any angle $\theta_{z}$ ), and that crossed when the sun is at the Zenith [11], [12]. Therefore, this can also be taken as the ratio between the segment $\Delta z$ and the segment $\Delta h$, crossing an atmospheric layer of thickness $\Delta h_{i}$ and characterized by a constant extinction $\alpha_{i}$.

Therefore, it is possible to write that

$$
\Delta z_{i}=\operatorname{AM}_{\mathrm{REL}}\left(\vartheta_{Z}\right) \Delta h_{i}
$$

where for small angles $\theta_{z}$

$$
\operatorname{AM}_{\mathrm{REL}}\left(\vartheta_{Z}\right)=\frac{1}{\cos \left(\vartheta_{Z}\right)}
$$

while for larger values of $\theta_{z}$, Young [13] developed the following relation, (5) as shown at the bottom of this page.

The solar Zenith angle $\theta_{z}$ can be computed, from the time (day of the year and hour of the day) and the location (latitude and longitude) as described in [14]. The solar elevation angle is calculated as

$$
e=\operatorname{Arcsin}(\sin \varphi \sin \delta+\cos \varphi \cos \delta \cos H)
$$

where $\varphi$ is the observer geographical latitude, $\delta$ is the sun declination, and $H$ is the local hour angle.

The solar elevation angle is then related to the solar Zenith as

$$
\vartheta_{Z}=90^{\circ}-e .
$$

These equations can be back substituted in (2) to obtain

$$
I\left(h, \vartheta_{Z}\right)=I_{0} e^{\mathrm{AM}_{\mathrm{REL}}\left(\vartheta_{Z}\right) \sum-\alpha_{i} \Delta z_{i}} .
$$

The sum in (8) should include all the intervals in which $\alpha_{i}$ is significant, and here only the first $50 \mathrm{~km}$ of atmosphere is considered, beyond which the extinction parameter becomesfor our purpose-negligible, and the intensity of the radiation $\left(I_{0}\right)$ is assumed constant and equal to $1367 \mathrm{~W} / \mathrm{m}^{2}$.

The sun beam entering the Earth's atmosphere encounters initially a clear atmosphere, as clouds are usually only in the lowest few kilometers. Therefore, the initial stage of the computation is to consider a clear atmosphere (next section), and then, below a certain altitude the extinction parameter is modified to consider the influence and filtering effect of the clouds.

1) Extinction for Clear Atmosphere: The extinction data $\left(\alpha_{i}\right)$ in clear sky conditions are provided by Elterman [15] and using (8) it is possible to work out the value of the beam irradiance at various altitudes in clear sky.

Alternatively, it is possible to simplify (8), considering the total extinction produced crossing the whole air mass of the atmosphere

$$
\alpha_{\mathrm{INT}}=\sum\left(\alpha_{i} \Delta h_{i}\right)
$$

and rather than calculating $\alpha_{\mathrm{INT}}$ from the summation of the extinction parameters through the whole atmosphere (described by the $\alpha_{i}$ series), $\alpha_{\text {INT }}$ can be calculated starting from the standard test conditions, which are used to evaluate the performance of commercial PV systems. In these conditions, a panel is illuminated with an intensity of $1000 \mathrm{~W} / \mathrm{m}^{2}$ at a temperature of $25{ }^{\circ} \mathrm{C}$ with a relative air mass of 1.5 . The $1000 \mathrm{~W} / \mathrm{m}^{2}$ are the global radiation, i.e., direct beam component plus diffused radiation, and beam component is around $85 \%$ of the global, reaching a value of about $850 \mathrm{~W} / \mathrm{m}^{2}$ [16], [17]. With these values, and $I_{0}=1368 \mathrm{~W} / \mathrm{m}^{2}$ the value of $\alpha_{\mathrm{INT}}$ can be obtained $\left(\alpha_{\mathrm{INT}}=0.32\right)$.

Therefore, (8) can be rewritten as

$$
I\left(\vartheta_{Z}\right)=I_{0} e^{-\mathrm{AM}_{\mathrm{REL}}\left(\vartheta_{Z}\right) \alpha_{\mathrm{INT}}}
$$

and it can be used to determine the irradiance that reaches the ground, depending on the value of the relative air mass (and the solar Zenith angle).

In order to be able to calculate the beam irradiance at an altitude $h_{0}$, as shown in Fig. 1(b), (10) has to be modified to consider the fact that only a portion of the air mass is above the altitude $h_{0}$. As a first approximation this portion can be assumed as proportional to the ratio between the pressure at the altitude $h_{0}$ and pressure at ground level (i.e., to the relative pressure at $h_{0}$ ). Therefore, using the description of the standard troposphere

$$
p_{\mathrm{REL}}\left(h_{0}\right)=\left(\frac{p_{h}}{p_{0}}\right)=\left(\frac{T_{0}-0.0065 h_{0}}{T_{0}}\right)^{5.2561}
$$

where $T_{0}=288.16^{\circ} \mathrm{K}\left(15^{\circ} \mathrm{C}\right)$.

This term can be included in (9) to give the beam irradiance in clear sky at any altitude $h_{0}$

$$
I\left(h_{0}, \vartheta_{Z}\right)=I_{0} e^{-p_{\mathrm{REL}}\left(h_{0}\right) \mathrm{AM}_{\mathrm{REL}}\left(\vartheta_{Z}\right) \alpha_{\mathrm{INT}}} .
$$

$$
\operatorname{AM}_{\mathrm{REL}}\left(\vartheta_{Z}\right)=\frac{1.002432 \cos \left(\vartheta_{Z}\right)^{2}+0.148386 \cos \left(\vartheta_{Z}\right)+0.0096467}{\cos \left(\vartheta_{Z}\right)^{3}+0.149864 \cos \left(\vartheta_{Z}\right)^{2}+0.0102963 \cos \left(\vartheta_{Z}\right)+0.000303978} .
$$




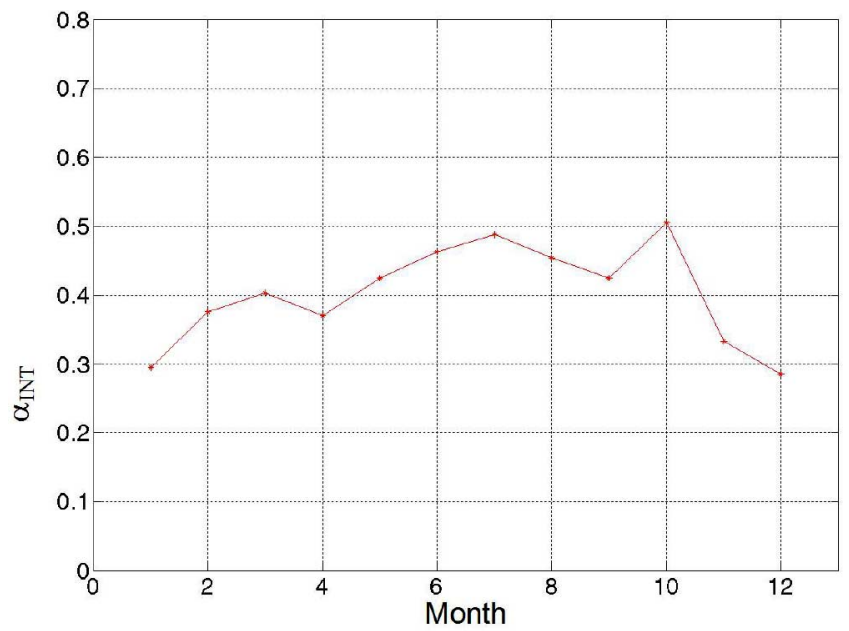

Fig. 2. Monthly variation of the total extinction $\alpha_{\mathrm{INT}}$ obtained from ground data.

The results obtained using this equation, are indeed very close to those obtained using (8). Finally, to improve correlation with the data from ground observation, the value of $\alpha_{\text {INT }}$ in (12) can be modified to include its variation during the various months of the year. The dataset to calculate the monthly values of $\alpha_{\text {INT }}$ were provided by photovoltaic geographical information system (PVGIS) [18]. The new values of $\alpha_{\text {INT }}$ are shown in Fig. 2, and they can be used in (12) to calculate the beam irradiance for the various months.

So far the calculations reflect clear sky conditions, and if the aerostat was stationed "always" above the clouds (say at $12 \mathrm{~km}$ ), these equations would be sufficient to calculate the beam irradiance. However, practical reasons (e.g., to limit interference with international air traffic) may require that the aerostat be stationed at a lower altitude $(6 \mathrm{~km})$, and here at times (although not very often), there is the possibility of clouds obscuring the sun. Therefore, values of extinction for the actual atmosphere (including clouds) have to be used, as shown in the next section.

2) Actual Atmosphere Extinction: The dataset supplied by the Cloudnet project contains the extinction parameters from the measurements acquired at Chilbolton Observatory, U.K. Fig. 3 shows an example of the data obtained, describing the extinction parameter during the month of May 2003.

The data are obtained from Radar/Lidar measurements at altitudes between 0 and $12 \mathrm{~km}$. The observations were performed almost everyday of the year (from April 2003 to September 2004), 24 hours a day.

The extinction data from the Chilbolton observatory are then substituted into the data for the clear atmosphere, as shown in Fig. 4, which represents the average for the month of March.

The integration of the beam irradiance during the day (from sunrise to sunset), leads to the determination of the total beam energy (beam irradiation $E_{B}$ ) that falls on a surface located at different altitudes above the sea level (Fig. 5), and sun pointing

$$
E_{B}(h)=\int_{\mathrm{SR}}^{\mathrm{SS}} I_{B}(h) d t
$$

where SS and SR indicate sunset and sunrise.
Fig. 5 shows the beam irradiance for 6 and $12 \mathrm{~km}$ altitude, compared to the irradiance for typical ground-based PV systems, and SSP. The integration of the data for the case of $6 \mathrm{~km}$ altitude is shown in Table I, where it can be seen that a direct beam irradiation of about $3545 \mathrm{kWh} / \mathrm{m}^{2}$ can reach this altitude.

\section{B. Global Irradiation and PV Device Output Estimation}

In order to calculate the total energy that reaches the PV surface (global irradiation), the diffused component of the irradiation has to be summed to the beam component calculated in the previous section. The diffused component can be a significant portion of the global irradiation, especially considering a ground-based PV systems under overcast sky.

The ratio between diffuse and global radiation that reaches the ground usually varies for different months, and, for example, for Southampton, the diffused component in total is actually more than half of the total radiation (data provided by PVGIS [18]).

Considering clear atmosphere conditions, the ratio between diffuse and global radiation is much less and can be assumed to have a value of about $20 \%$ [16], [17], while for a satellite in LEO (low Earth orbit) it can be considered about 10\% [19] (here, the radiation is actually diffused/reflected by the Earth).

In order to estimate the diffused radiation at altitudes between 6 and $12 \mathrm{~km}$, the conservative assumption that the atmosphere crossed by the light beam is clear is made, and therefore the contribution of the diffused radiation will be between $10 \%$ and $20 \%$. The interpolation is then carried out according to the air mass (proportional to the relative pressure) that will be above the specific altitude, so that a value of about $15 \%$ can be taken for an altitude of $6 \mathrm{~km}$. Following the same approach, a value of $13.5 \%$ and $12.5 \%$ can be assumed for 9 and $12 \mathrm{~km}$, respectively. These diffused radiations are then summed to be beam component (calculated in the previous section) to obtain the resulting global radiation that in turn allows to calculate the energy output.

Finally, taking a typical $1 \mathrm{kWp}$ system, with PV cell having $15 \%$ efficiency (which means a surface of about $7 \mathrm{~m}^{2}$ ), the output that can be expected in the various situations is shown in Table II.

\section{High-Altitude Winds}

The knowledge of the mean wind speed at a certain altitude (and its statistical properties) is essential to calculate the aerodynamic forces acting on the aerostat and in particular to determine the forces along the mooring cable.

The wind speed data described in this section were provided by the Natural Environment Research Council (NERC), from the Mesosphere-Stratosphere-Troposphere (MST) radar station located at Capel Dewi $\left(52.42^{\circ} \mathrm{N}, 4.01^{\circ} \mathrm{W}\right)$, near Aberystwyth in west Wales, U.K. This facility can provide vertical and horizontal wind speed data, covering an altitude range from 2 to $20 \mathrm{~km}$, with $300 \mathrm{~m}$ resolution. However, for this paper, only the data up to $10 \mathrm{~km}$ were processed. The particular set of data described here covers the period January-December 2007, and measurements were acquired everyday continuously. The radar is located near the coast, where the wind speed is expected to 

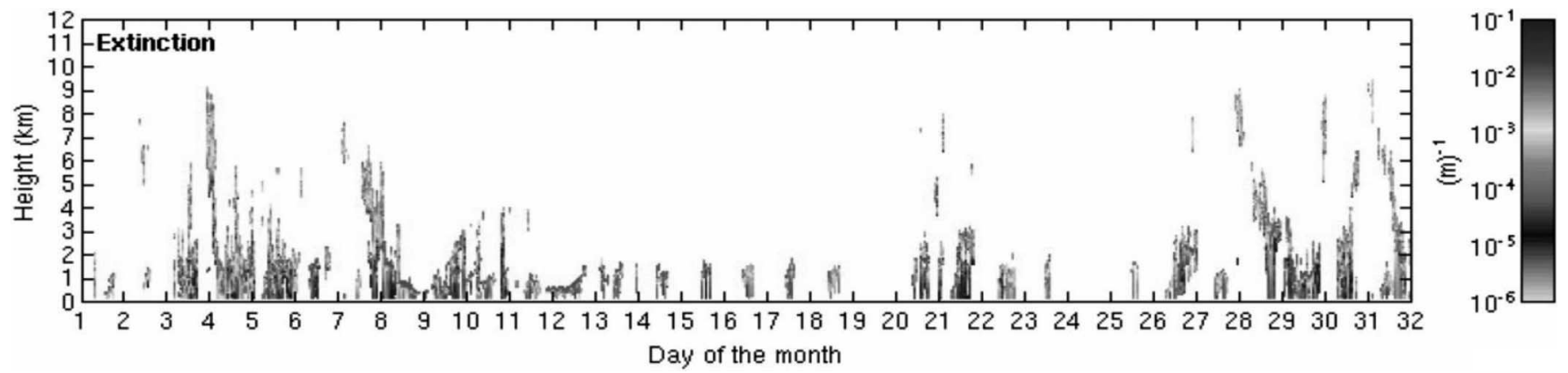

Fig. 3. Extinction parameter acquisition sample (May 2004) Cloudnet Project.

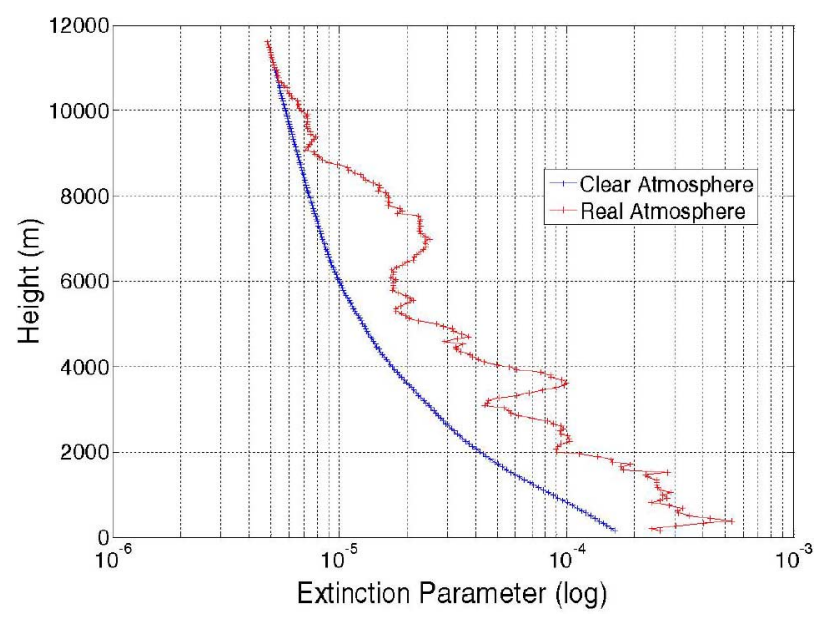

Fig. 4. Extinction parameter in clear and real atmosphere conditions.

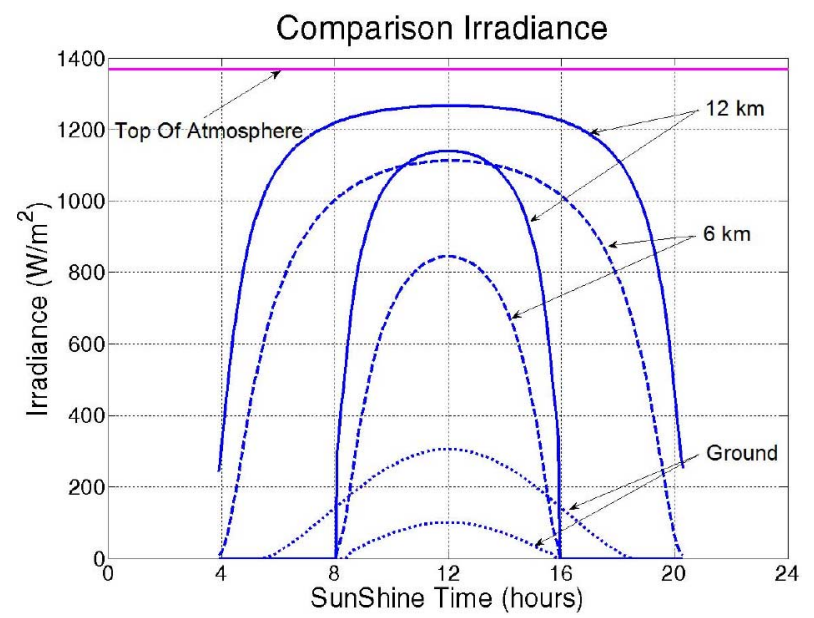

Fig. 5. Comparison between beam component irradiance at ground level, $6,12 \mathrm{~km}$, and outside the atmosphere (SSP). For each altitude, the two lines represent the maximum and minimum monthly average.

be slightly higher than inland, and therefore the estimate should be conservative.

Fig. 6 shows the mean wind speed and the 3 sigma value, and it is possible to notice that at $6 \mathrm{~km}$ altitude these values are 20 and $55 \mathrm{~m} / \mathrm{s}$, respectively.

Another factor to be considered is that, in the time domain (see Fig. 7), the wind speed is quite variable with relatively rapid
TABLE I

MEAN DAILY AND TOTAL BEAm IRRAdiation AT 6 km

\begin{tabular}{|c|c|c|}
\hline Period & $\begin{array}{c}\text { Mean Daily Beam } \\
\text { Irradiation at } 6 \mathrm{~km} \\
{\left[\mathrm{kWhh} / \mathrm{m}^{\wedge} 2\right]}\end{array}$ & $\begin{array}{c}\text { Total Monthly Beam } \\
\text { Irradiation at } 6 \mathrm{~km} \\
{\left[\mathrm{kWh} / \mathrm{m}^{\wedge} 2\right]}\end{array}$ \\
\hline January & 5.2 & 161 \\
\hline February & 7.5 & 209 \\
\hline March & 10.1 & 313 \\
\hline April & 12.8 & 383 \\
\hline May & 13.7 & 423 \\
\hline June & 14.0 & 421 \\
\hline July & 14.7 & 456 \\
\hline August & 12.5 & 389 \\
\hline September & 9.7 & 290 \\
\hline October & 6.6 & 205 \\
\hline November & 4.9 & 148 \\
\hline December & 4.8 & 148 \\
\hline Year & 9.7 & $\mathbf{3 5 4 5}$ \\
\hline
\end{tabular}

TABLE II

EXPECTED OUTPUT FROM $1 \mathrm{kWp}$ PV DEVICE AT DIFFERENT LOCATIONS

\begin{tabular}{|c|c|}
\hline Altitude & $\begin{array}{c}\text { Yearly output from 1kWp facility, } \\
\text { assuming operation in Standard } \\
\text { Conditions [kWh] }\end{array}$ \\
\hline Ground Based & $\begin{array}{c}1130^{*} \\
(750-900)^{* *}\end{array}$ \\
\hline $6 \mathrm{~km}$ & 4170 \\
\hline $12 \mathrm{~km}$ & 5480 \\
\hline $\begin{array}{c}\text { Geostationary } \\
\text { (Solar Power Satellite) }\end{array}$ & 12000 \\
\hline
\end{tabular}

*Value directly calculated from the irradiation at Southampton.

** Practical values suggested by manufacturers of PV for installations in U.K.

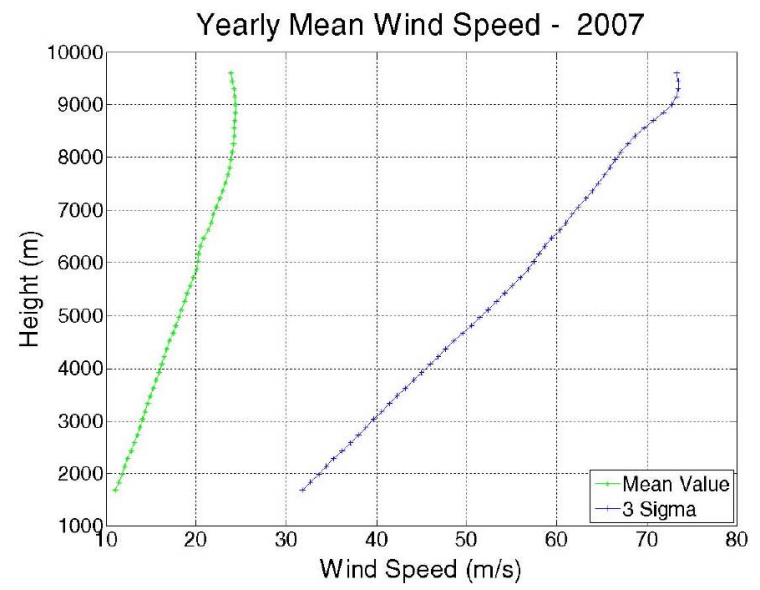

Fig. 6. Wind speed variation with altitude. Year mean and 3 sigma value. 


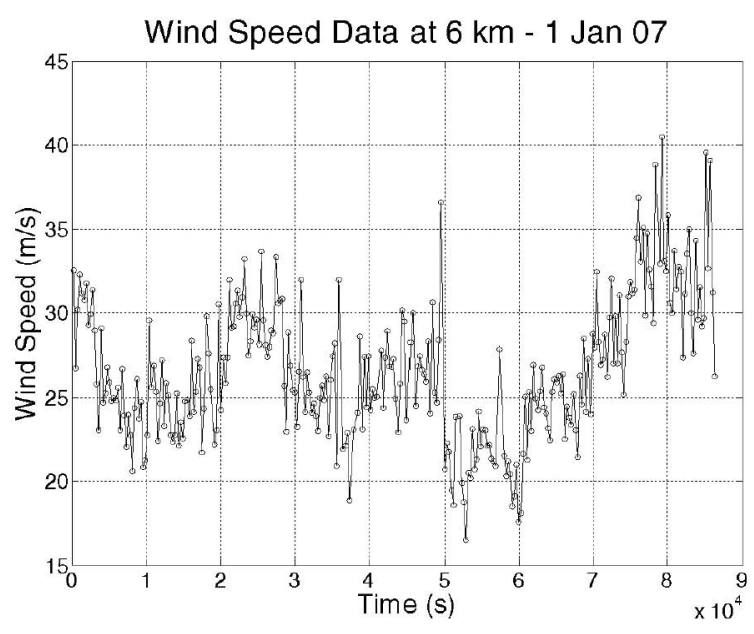

Fig. 7. Wind speed variation with time.

transients (i.e., gusts). As discussed in detail in [20], the tethered aerostat is a nonlinear system, with considerable damping, and therefore rapid transients of the input in reality produce a response that is significantly lower than what is calculated simply using the maximum wind speed in a static analysis.

\section{Aerostat Concept Design}

The aerostat has to be able to produce enough lift via its buoyancy to overcome its weight, the weight of the solar cells plus any control system, and that of the tether, still leaving enough margin to produce an appropriate tension in the tether to avoid excessive sag.

Neglecting any aerodynamic lift that could be generated by the shape of the aerostat, the lifting force due to the aerostat buoyancy is

$$
B=\left(\rho_{\text {air }}-\rho_{\text {gas }}\right) g \mathrm{Vol}
$$

where Vol is the volume of the aerostat and $\rho_{\text {air }}$ and $\rho_{\text {gas }}$ the densities of air and gas (helium or hydrogen can be used) filling the aerostat envelope at the specific conditions of operations (e.g., pressure, altitude), and $g$ is the gravity acceleration $\left(9.81 \mathrm{~m} / \mathrm{s}^{2}\right)$. Here, it is assumed that there is a negligible pressure differential between inside and outside the aerostat envelope, and for simplicity, it is also taken that the whole volume of the envelope is occupied by the gas (i.e., ballonets for altitude control completely empty).

As the aerostat PV cells clad area has to track the Sun, typical streamlined shapes are not the best solution as these will tend to behave like a weathervane and considerable control effort would be required to maintain Sun pointing. A spherical shape would not generate significant aerodynamic moments and therefore its pointing through a system of gimbals requires minimal control effort (see Fig. 8). A spherical aerostat generates more aerodynamic drag and clearly would require a more substantial structure and tether, but these issues can be tackled by its structural design [21]. A tethered sphere also suffers substantial vortex-induced vibrations [22]. However, a previous study [20] has shown that due to the nonlinearity of the structural problem

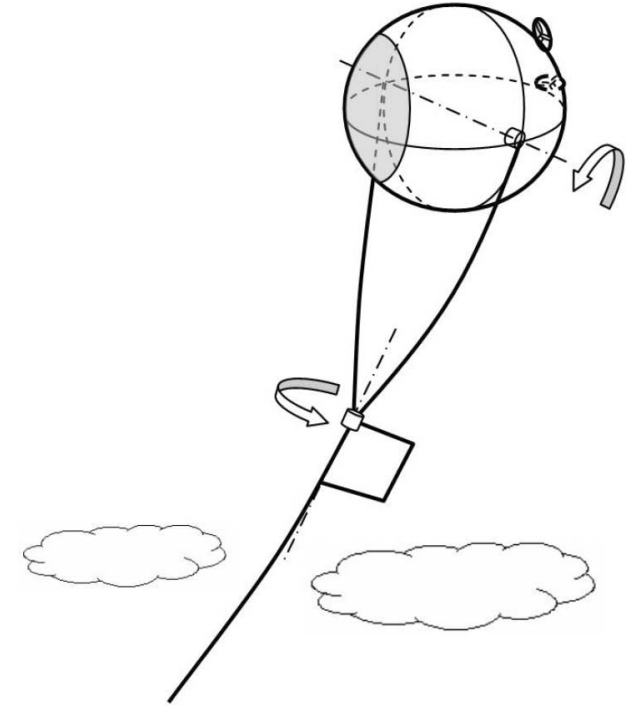

Fig. 8. Schematic configuration of an aerostat for electrical power generation (ASPG), as a gimballed tethered balloon-the gray area represents PV cells cladding.

(mainly the sag of the tether) and the very slow frequency response characterized by a high value of damping, the force oscillations in the tether (produced by relatively rapid force transients, e.g., gusts) line are relatively small and also the rotations of the aerostat are only a few degrees and the consequent loss of pointing produces a drop in the energy production of less than $1 \%$.

Given its spherical shape, from the volume it is possible to calculate the surface area, and from this, taking an appropriate material area density, it is possible to estimate the weight of the envelope. The area density of the material for the skin can then be increased by $33 \%$ as suggested in [23], to account for the weight of various reinforcements, support for the payload, etc.

With a similar approach, the weight of the PV cells can be estimated by the surface covered, and assuming that a fraction $\gamma$ of the whole aerostat envelope is covered by the cells, knowing the area density of the cells (also here including wiring, etc.), it is possible to estimate the weight of the cells. Therefore, the weight of aerostat and PV devices can be written as

$$
W_{\text {aero }}=\left(1.33 \delta_{\text {aero }}+\delta_{\text {cells }} \gamma\right) g 4 \pi \mathrm{R}^{2}
$$

where $\delta_{\text {aero }}$ and $\delta_{\text {cells }}$ are the area density of the envelope material and PV cells, respectively, $\gamma$ is the fraction of the envelope surface that is covered by the PV cells, $g$ is the gravity acceleration, and $R$ is the radius of the balloon.

To assess the weight of the tether, it is necessary to estimate the weight of the electrical conductors (taken as aluminum for this high conductivity over mass ratio) plus that of the strengthening fibers (e.g., some type of Kevlar). The size of the required conductor can be estimated from the electrical current (i.e., the ratio between the power generated by the PV devices on the aerostat and the transmission voltage) and setting the electrical losses permitted in the cable to a specific value. Therefore, the 
cross section of the conductor will be

$$
A_{\text {cond }}=r_{\mathrm{Al}} \frac{S}{\eta_{\text {trans }}} \frac{P_{\text {gen }}}{V^{2}}
$$

where $r_{\mathrm{Al}}$ is the resistivity of the aluminum, $S$ is the overall length of the conductor, $\eta_{\text {trans }}$ is the ratio between the power lost in the cable and that generated by the PV devices (i.e., $P_{\text {gen }}$ ), and $V$ is the voltage.

The power generated by the PV system can be estimated from the area covered by the cells (i.e., a fraction $\gamma$ of the whole aerostat surface), their efficiency $\left(\eta_{\text {cells }}\right)$, an efficiency parameter $\left(\eta_{\text {area }}\right)$ that considers that the cells are on a curved surface and therefore the angle of incidence of the sun beam varies according to the position of the cells, and finally the solar flux $\Phi$ at the aerostat operational altitude, i.e., the irradiance discussed in the previous sections

$$
P_{\text {gen }}=4 \pi \mathrm{R}^{2} \gamma \eta_{\text {cells }} \eta_{\text {area }} \Phi .
$$

Finally, the weight of the conductor will be its cross-sectional area multiplied by length and by its specific weight (density times $g$ ), so substituting (17) in (16) the weight of the conductor can be written as

$$
W_{\text {cond }}=\delta_{\mathrm{Al}} g r_{\mathrm{Al}} \frac{S^{2}}{\eta_{\text {trans }}} \frac{4 \pi \mathrm{R}^{2} \gamma \eta_{\text {cells }} \eta_{\text {area }} \Phi}{V^{2}}
$$

The weight of the reinforcing fibers can be calculated from the strength necessary to keep the aerostat safely moored. The maximum tensile force on the tether can be calculated as

$$
T=\sqrt{\left(B-W_{\text {Aero }}\right)^{2}+D^{2}}
$$

where $D$ is the aerostat drag force, given by

$$
D=\frac{1}{2} \rho_{\mathrm{air}} v^{2} C_{d} \pi R^{2} .
$$

In this expression, $v$ is the maximum wind velocity and $C_{d}$ is the drag coefficient. From the maximum expected tension in the tether, knowing the fibers strength $\left(\sigma_{u}\right)$, it is possible to calculate the required cross section and from that the weight of the reinforcing fibers

$$
W_{\mathrm{fib}}=\delta_{\mathrm{fib}} S_{T} \frac{T}{\sigma_{u}}
$$

where $\delta_{\mathrm{fib}}$ is the density of the fibers and $S_{T}$ the length of the tether.

So that the overall weight of the tether will be

$$
W_{\text {tether }}=\delta_{\text {cond }} g r_{\text {cond }} S^{2} \frac{\eta_{\text {cells }} \eta_{\text {area }} A_{\text {cells }} \Phi}{\eta_{\text {trans }} V_{\text {gen }}^{2}}+\delta_{\text {fib }} S_{T} \frac{T}{\sigma_{u}} \text {. }
$$

Aerodynamic forces will also act on the tether line, and they will produce further sagging (see [20]). However, this effect does not modify significantly the maximum tension in the tether that will still be at the attachment between the balloon and the tether (19).

\section{A. Engineering Parameters Selection}

The most important design variable that has to be set is the operational altitude of the aerostat. From Section II, it can be seen that, although infrequently, it is still possible to find clouds above $6 \mathrm{~km}$, and in rare cases the cloud top could extend up to $20 \mathrm{~km}$. However, from a practical engineering prospective, the technical performance has to be traded against cost and it is possible that a slightly lower performance in terms of energy production would significantly reduce the cost. In addition, there are safety and regulatory issues such as the interference with air traffic that would advise limiting the altitude to $6 \mathrm{~km}$ to stay below the internationally controlled air traffic.

In order to facilitate the commercialization of the concept the maximum altitude will be set to $6 \mathrm{~km}$. The next important parameter is the size (or the volume) that defines the amount of lift (buoyancy) that can be produced, and as most of the weights are proportional to the aerostat surface area there will be a minimum size where the lift and weights are balanced. In order to maintain the tether taut (and limit the drift produced by the wind), it is necessary to generate considerably more lift so that

$$
B>W_{\text {Aero }}+W_{\text {Tether }}
$$

However, as the energy produced is proportional to the surface area, whereas some of the cost elements are proportional to the volume, very large aerostats would be less cost-effective.

Taking a volume of $179000 \mathrm{~m}^{3}$ (i.e., a $35 \mathrm{~m}$ radius sphere) and helium as a gas filler would give a buoyancy of $1 \mathrm{MN}$. Using for the aerostats structure parameters consistent with reference [23] (i.e., weight of the skin $0.78 \mathrm{~kg} / \mathrm{m}^{2}$, weight of the PV cells cladding $1 \mathrm{~kg} / \mathrm{m}^{2}$, and a maximum peak solar irradiation (from Section II) of $1.2 \mathrm{~kW} / \mathrm{m}^{2}$ ), from the equations in the previous section, it is possible to calculate $\mathrm{W}_{\text {Aero }}\left(18.9 \times 10^{3} \mathrm{~kg}\right)$ and the peak power generated $(\sim 0.5 \mathrm{MW})$. However, to size the conductor in the tether, it is necessary to set a transmission voltage $\mathrm{V}$, and this should be high enough in order to reduce the losses in the cable. One option is to connect the solar arrays to obtain a voltage in the region of $500 \mathrm{~V}$ dc and use a converter to bring it up to a few kilovolts. However, the converter will introduce some electrical losses and its weight might be an issue as it has to be supported by the aerostat (although the weight of the converter might be compensated by a lighter cable). The other option is to "simply" connect identical groups of solar arrays in series, to maintain the same current and obtain a dc voltage in the region of $1.5-3 \mathrm{kV}$. The solar panels would be provided with bypass and blocking diodes and other circuitry that might be necessary to protect the elements of the system. Setting the transmission voltage at $3 \mathrm{kV}$ and allowing for $5 \%$ electrical losses in the cable (i.e., $\eta_{\text {trans }}=0.05$ ) enables the cross section of the aluminum conductor and its weight to be calculated as $388 \mathrm{~mm}^{2}$ and $13.0 \times 10^{3} \mathrm{~kg}$, respectively.

Using the results in Section III and taking a maximum wind speed of $55 \mathrm{~m} / \mathrm{s}$ (3 sigma value) and using (21), it is possible to calculate the weight of the fibers as $2.7 \times 10^{3} \mathrm{~kg}$, so that the overall weight of the tether will be $15.7 \times 10^{3} \mathrm{~kg}$. It should be stressed that the $55 \mathrm{~m} / \mathrm{s}$ value is quite conservative, in fact, this corresponds to the peak wind speed during a gust and due to the highly nonlinear behavior of the tether system (see [20]) the force in the tether will be considerably smaller. On the other 
hand, this level of conservatism is more than justified by the catastrophic effect that the tether rupture would have.

\section{B. System Dynamics and Control}

The aerostat is required to track the sun, although the accuracy of the tracking can be relatively coarse. In fact, as the power produced by the beam component of the irradiance depends on the cosine of the angle between the perpendicular to the PV cells and the solar beam, even a pointing error of $\pm 8^{\circ}$ would only produce a drop of this component of less than $1 \%$. For these relatively small angles, the diffused component of the irradiance would be roughly the same, so that the impact of small pointing errors on the total energy should be negligible.

The tracking must be maintained in the presence of dynamic disturbances that are mainly gusts and vortex-induced vibrations. The amplitudes of the rotations produced by these disturbances are discussed in [20], which shows very small rotation (in the worst case considered the angle was below $8^{\circ}$ ). Therefore, the attitude control system does not need to compensate for these disturbances, but simply work at low frequency to track the sun movement. As the aerostat is spherical, no significant aerodynamic torque must be overcome. The friction in the gimbals bearing is also very small and so is the resistive torque produced by the balloon's inertia multiplied by the rotational accelerations necessary to carry out the tracking.

The pointing mechanism concept is illustrated in Fig. 8, where it is possible to see its gimballed configuration, with the spherical body of the aerostat constrained by rotational joints (driven by geared electric motor/s) on two opposite locations of its equatorial line. This allows control of the elevation; while the azimuth is controlled rotating the small rudder visible in Fig. 8 and that will line itself up with the wind direction. Alternatively, the rotations of the aerostat can be controlled using the fans/propellers visible behind the aerostat (Fig. 8) that produces forces tangential to its surface (thus rotating the aerostat). This method is employed in those circumstances where low wind makes the rudder control ineffective. The system is controlled using a feedback loop that drives elevation and azimuth controls using information provided by solar sensors on the aerostat and which give the relative position of the sun with respect to the aerostat body. A patent application has currently been submitted (patent application U.K. IPO number 0713045.3), and therefore, at this stage, it is not possible to disclose further information concerning the pointing mechanism. A preliminary costing for the implementation of this mechanism on a balloon of the size discussed in the previous section delivered a figure lower than $100000 \$$.

\section{Risk Management}

The deployment of ASPG indeed involves some risks, the most obvious being lighting strikes and interference with aviation. These problems are common to other FEG and to the aerostats currently in operation, such as those deployed in the south of the USA carrying radars to monitor air traffic coming from the Central and South America. These aerostats implement lighting protection systems and to avoid collision with air traffic they are signaled in aeronautical charts and can carry visible or electronic warning systems. In case of extreme weather, it is possible to ground the aerostat, and similarly in the extreme circumstances an appropriate deflation system enables the aerostat to be brought back to the ground quickly and safely. Just as an historical note, during the Second World War tethered barrage balloons were deployed in Britain, fitted with protection against lightning (up to $30 \mathrm{kA} \cdot \mathrm{m} \cdot \mathrm{s}$ ) that took care of approximately $75 \%-80 \%$ of the strokes [24]. The "double parachute/Ripping" was also developed, to allow (in emergency) the cable to be ripped from the balloon and fall to the ground slowed down by a parachute.

Should these devices be deployed in a farm configuration the distance between balloons becomes critical to avoid them hitting each other. The large scale of the turbulence in the atmosphere is such that balloons flying in relative proximity are subjected to very similar wind conditions (magnitude and direction). In this case, the relatively high disposable lift (which maintains the mooring cable taut) also helps to limit the balloon drift. Therefore, a grid of identical tethered balloons should approximately keep the same configuration maintaining the relative positions of the various balloons. Clearly, there will be fluctuations in the distance between balloons and different wind conditions for each balloon, also due to the wake of the balloons upwind striking balloons downwind. However, our preliminary calculations have shown that the distance between the balloons can be kept in the region of a few hundred meters, rather than kilometers. Last resort solution to keep relatively small and constant distance between balloons is multipoint mooring and bracing between balloons. In this case, the advantages of a more tightly compact grid of balloons have to be offset by the increased technical difficulties (for example, to ground a single balloon of the grid) and cost of this solution.

\section{Costing}

Due to the relatively early stage of the design, it is quite difficult to establish the exact cost of the system described in the previous sections. However, a reasonable estimate can be obtained from the unit cost of the materials and/or extrapolating from the cost of similar systems/subsystems available on the market. Starting from the Aerostat, the cost of solar cells partial cladding and the cost of the gas filler can be obtained easily from their unit costs $\left(4 \$ / \mathrm{W}\right.$ for the cells and $5 \$ / \mathrm{m}^{3}$ for the helium, respectively). The cost of the aerostat envelope and internal subsystems (e.g., balloonette for altitude control) can be obtained by extrapolating from the cost of other aerostats available in the market. Using weight as parameter to extrapolate the cost, based on a survey of aerostats currently on the market, it is estimated that 2 million dollars (excluding gas and PV cells) should cover the envelope cost. It should also be stressed that today there are only a relatively small number of commercial companies that produce airships or aerostats, and their sales are mainly for the military market, rather than for civil applications. Most of the products are heavily customized with characteristics and payloads to suit the need of the specific customers, resulting in unique combinations of hull, subsystems, and payload. 
Therefore, the number of "build to print" is very limited and the nonrecurring costs are very high compared with the cost of the "materials." In addition, the aerostat advocated here is essentially a sphere filled in with helium, and therefore much simpler than most of the aerostats currently on the market.

To maximize the profit, the system must be maintained in operation ideally for a time similar to the duration of the solar cells (which is around 15 years), and therefore maintenance and ground support will be necessary. For an aerostat, the item most subject to degradation is the hull, where the damage is mainly produced by the solar radiation. However, here the part of the aerostat exposed to the sun is mostly covered by the solar cells, and this should significantly reduce the material degradation. Concerning helium leakages, using modern materials, it is possible to reduce the total loss to a fraction of a meter cube per day, which means that even six months of continuous operation would produce only a negligible loss of lift.

The system is designed to be autonomous; therefore the running cost should be minimal, and essential maintenance if possible should be carried out at night or in good weather in order not to produce interruption of the energy harvesting. The grounding for extreme weather conditions will also be rare, say approximately 14 days/year on average, and as this will mostly be in the winter (with shorter daylight) also the impact on the production will be limited. Overall, the complete system should cost in the region of 4.5 million dollars, but it must be stressed that this is the cost for the production of a single unit. It is likely to imagine applications (like "farms") with several identical balloons deployed, and this would dramatically reduce their unit cost. Deployment of the system described in Section IV at $6 \mathrm{~km}$ would allow production of about $1.7 \times 10^{6} \mathrm{kWh} /$ year. In addition, to be conservative, this design has considered $15 \%$ efficiency cells. However, in the market there are cells whose efficiency approaches $30 \%$ and therefore should this type of cells be used, the facility outlined in this paper would produce nearly twice as much energy.

If the aforementioned system ( $\sim 0.5 \mathrm{MW}$ output) could be maintained in operation for say 15 years the cost of the energy produced could be in the region of 17 cents/kWh. However, if several units are produced, the lower cost per unit would considerably reduce the cost of the energy, and their deployment in a "farm" configuration could produce several megawatts that is comparable to the current wind farms. Considering that in the U.K., the cost of solar energy is approximately $1 \$ / \mathrm{kWh}[25]$, this concept could present a considerable advantage. This advantage is reduced for countries that enjoy naturally higher solar radiations (e.g., Mediterranean countries, or southern states of the USA) where solar energy produced on the ground can cost in the region of 20-30 cents/kWh.

With respect to other typical renewables (e.g., wind turbines) whose cost per kilowatthour produced in the U.K. is about 10-20 cents/kWh, with even lower cost achievable in other countries, the economical advantage is less obvious. However, there are other advantages such as the predictability/reliability of the energy production and its better synchronization with the daily cycle of electric energy consumption that could make harvesting high-altitude solar power a preferable option. Finally, also the impact on the ground is much more limited, making this facility an option for areas with unsuitable grounds, for example, subjected to flooding; although this advantage has to be offset by the negative impact on air traffic.

\section{CONCLUSION}

This paper has examined the possibility to harvest solar energy in the high atmosphere, as an intermediate solution between ground-based PV devices and SSP. Based on the real data concerning the extinction parameters in the Earth's atmosphere, it has been demonstrated that at altitudes above $6 \mathrm{~km}$, it is possible to produce over four times the energy that is usually produced by ground-based PV in the U.K. Compared with SSP the method advocated in this paper allows to collect between one-third and half of what could be collected by a geostationary satellite collector (for the same size of PV system). However, the cost of SSP is orders of magnitude higher than the solution advocated here. Based on the realistic values of the relevant engineering parameters, a concept design has been presented, and its preliminary costing has shown that ASPG could be a viable facility to harvest renewable energy.

\section{ACKNOWLEDGMENT}

The authors would like to acknowledge the support of the Cloudnet project (European Union contract EVK2-200000611) for providing the Ice Water Content and Particle Size (Radar/Lidar Method) Dataset, which was produced by Royal Dutch Meteorological Institute (KNMI) using measurements from the Chilbolton Facility for Atmospheric and Radio Research, part of the Rutherford Appleton Laboratory.

We also acknowledge the support of the MST Radar Facility at Aberystwyth funded by the U.K. NERC and the British Atmospheric Data Centre for providing the data concerning the wind statistics.

\section{REFERENCES}

[1] K. Kurokawa, Energy From the Desert: Feasibility of Very Large Scale Photovoltaic Power Generation (VLS-PV) Systems. London, U.K.: Earthscan Publications Ltd., May 2004.

[2] P. E. Glaser, O. E. Maynard, J. Mackovciak, and E. L. Ralph, Feasibility Study of a Satellite Solar Power Station. Cambridge, MA: Arthur D. Little, Inc., Feb. 1974 (NASA CR-2357, NTIS N74-17784).

[3] J. C. Mankins, "A fresh look at space solar power: New architectures, concepts and technologies," presented at the 38th Int. Astronautical Congr., Washington, DC, 1997, IAF Paper IAF-97-R.2.03.

[4] G. S. Aglietti, T. Markvart, A. R. Tatnall, and S. J. Walker, "Aerostat for electrical power generation concept feasibility," in Proc. IMechE Part G, J. Aerosp. Eng., Feb. 2008, vol. 222, pp. 29-39.

[5] G. S. Aglietti, T. Markvart, A. R. Tatnall, and S. J. Walker, "Solar power generation using high altitude platforms feasibility and viability," Prog. Photovoltaics: Res. Appl., vol. 16, pp. 349-359, 2008.

[6] B. W. Roberts, D. H. Shepard, K. Caldeira, M. E. Cannon, D. G. Eccles, A. J. Grenier, and J. F. Freidin, "Harnessing high-altitude wind power," IEEE Trans. Energy Convers., vol. 22, no. 1, pp. 136-144, Mar. 2007.

[7] (2007). [Online]. Available: www.magenn.com/news.php

[8] K. N. Liou, An Introduction to Atmospheric Radiation (International Geophysics Series), vol. 84, 2nd ed. San Diego, CA: Academic, 2002.

[9] W. Knaupp and E. Mundschau, "Solar electric energy supply at high altitude," Aerosp. Sci. Technol., vol. 8, no. 3, pp. 245-254, Apr. 2004.

[10] (2008). [Online]. Available: http://www.cloud-net.org/

[11] L. F. Jesch, Solar Energy Today. London, U.K.: Int. Solar Energy Soc., U.K. Section, 1981. 
[12] B. J. Brinkworth, Solar Energy for Man. U.K.: Compton Press, 1972.

[13] T. Young, "Air mass and refraction," Appl. Opt., vol. 33, no. 6, pp. 1108$1110,1994$.

[14] I. Reda and A. Ashfin, "Solar position algorithm for solar radiation applications," Solar Energy, vol. 76, no. 5, pp. 577-589, 2004.

[15] L. Elterman, "Parameters for attenuation in the atmospheric windows for fifteen wavelengths," Appl. Opt., vol. 3, pp. 745-749, 1964.

[16] D. Felman, A. Karnieli, N. Ninari, V. Melnichak, and S. Jacob, "Using a natural AM1.5G spectrum to help define an AM1.5D spectrum appropriate for CPV purpose," in Proc. 29th IEEE Photovoltaic Spec. Conf., New Orleans, LA, May 2002, pp. 927-930.

[17] F. P. Baumgartner, J. Sutterluti, W. Zaaiman, T. Sample, and J. Meier, "Indoor and outdoor characterization of a-Si:H P-I-N modules," presented at the Eur. Photovoltaic Solar Energy Conf., Milan, Italy, Feb. 2007.

[18] (2001). [Online]. Available: http://re.jrc.ec.europa.eu/pvgis/

[19] B. Jackson, "A software power model for a spin-stabilized LEO spacecraft utilizing V/T charge control," in Proc. IEEE Aerosp. Appl. Conf., 1996, vol. 3, pp. 219-222.

[20] G. Aglietti, "Dynamic response of a high altitude tethered balloon system," submitted to the AIAA journal. Available: http:/www.soton.ac.uk/ses/ docs/publications/AIAA_aerostat.pdf

[21] J. I. Mille and M. Nahon, "Analysis and design of robust helium aerostats," AIAA J. Aircraft, vol. 44, no. 5, pp. 1447-1458, 2007.

[22] C. H. K. Williamson and R. G. Ovardhan, "Dynamics and forcing of a tethered sphere in a fluid flow," J. Fluids Struct., vol. 11, pp. 293-305, 1997.

[23] G. A. Khoury and J. D. Gillett, Airship Technology, (Cambridge Aerospace Series). Cambridge, U.K.: Cambridge Univ. Press, 2004.

[24] R. Davis and W. Standring, "Discharge currents associated with kite balloons," in Proc. Royal Soc. London, Math. Phys. Sci., 1947, vol. 191, no. 1026 , pp. 304-322.

[25] U.K. Department of Trade and Industry, Renewable Energy—Reform of the Renewables Obligation, U.K. Department of Trade and Industry, London, U.K., May 2007.

Guglielmo S. Aglietti graduated (with first class honors) in aeronautical engineering from Politecnico di Milano, Milan, Italy, in 1991, and the Ph.D. degree from the School of Engineering Sciences, University of Southampton, Southampton, U.K., in 2003.

He was first employed with Alenia Spazio in Turin, Italy. He then was with the European Space Research and Technology Centre (ESTEC) in Holland, and after that, in 1995, he joined the former Department of Aeronautics and Astronautic (now part of the School of Engineering Sciences), University of Southampton, where he was a Lecturer in 1999, became a Senior Lecturer, and is currently a Reader since 2008. Besides teaching aerospace structures and mechanisms to undergraduates, postgraduates, and industrial engineers, he was engaged in theoretical and experimental research work in various related areas (together with extensive consultancy work for industry). He is the author or coauthor of a total of 70 articles and two chapters in two books.

Dr Aglietti is a member of the Royal Aeronautical Society and the American Association of Aeronautics and Astronautics. He is a Chartered Engineer.

Stefano Redi received the B.Sc. and M.Sc degrees in aerospace engineering from the University of Padua, Padua, Italy, with a final project concerning the application of Kalman filtering techniques to intertia measurement unit-global positioning system (IMU-GPS) sensor fusion. He is currently working toward the Ph.D. degree at the Astronautics Research Group, School of Engineering Sciences, University of Southampton, Southampton, U.K.

He was a Vehicle Dynamic Engineer at the Aprilia Racing Department, Noale, Italy, in the Motorbike World Championship. He then joined the Astronautics Research Group, School of Engineering Sciences, University of Southampton, where is currently engaged in research on solar energy harvesting using highaltitude aerostatic platforms.
Adrian R. Tatnall received the B.Sc. degree in physics from Exeter University, Exeter, U.K., and the Ph.D. degree from Sheffield University, Sheffield, U.K. with the focus on "A satellite study of power line harmonic radiation, thunderstorm noise, and associated magnetospheric phenomena.

He was a Senior Space Systems Engineer at British Aerospace and was responsible for several contracts concerned with remote sensing instrumentation funded by the U.K. Meteorological Office. In 1988, he joined the Department of Aeronautics and Astronautics, University of Southampton, Southampton, U.K., where he is currently a Senior Lecturer in aerospace systems. He has carried out significant research work in various areas of Earth atmospheric physics and on atmospheric modeling to determine the microphysical properties of clouds For many years, he served on the Space Committee of the Royal Aeronautical Society, and is a Principal Investigator for the European Space Agency (ESA) Earth observation data. He is the author of over 100 journal and conference publications

Thomas Markvart received the B.Sc. and Ph.D. degrees in mathematica physics from the University of Birmingham, Birmingham, U.K., in 1971 and 1975, respectively.

After Research Fellowships at the Universities of Keele and Southampton, he spent two periods abroad at ONERA-DERTS, Toulouse and the Instituto de Energia Solar, Universidad Politecnica de Madrid. He became a Royal Academy of Engineering/EPSRC Clean Technology Fellow at Southampton in 1994. Since 2002, he has been a Reader in electronic materials and Director of the Solar Energy Laboratory in the School of Engineering Sciences, University of Southampton, Southampton, U.K. He is the author or couathor of a number of research papers and two books Solar Electricity (Wiley, Chichester, 1999) and Practical Handbook of Photovoltaics: Fundamentals and Applications (Elsevier, Oxford, 2006) in these fields. His current research interests include the device and system aspects of photovoltaic solar energy conversion and the environmental impact of energy technologies.

Dr. Markvart is a member of the Institution of Electrical and Electronic Engineers, Technical Advisor to the Institution of Engineering and Technology Professional Network on Power Conversion and Applications, member of the Council of the Tyndall Centre for Climate Change Research during 2000-2005, member of the International Advisory Board, Solar Energy Centre, Bulgarian Academy of Sciences in Sofia, and a member of the Advisory Board, Centre for Third Generation Photovoltaics, University of New South Wales during 2001. He was the Director of United Nations Educational Scientific and Cultural Organization (UNESCO)/British Council International Seminar on Development of Effective Solar Power Generation at Southampton in 1997. 